\section{The integration of health behavior counseling into routine medical care ${ }^{1}$}

Key words: Education in health, health systems, patients.

\footnotetext{
Based on: Center for the Advancement of Health. Integration of health behavior counseling in routine medical care. Washington, D.C.: CFAH; 2001. Available from: http://www.cfah.org [Internet site]. Accessed 5 June 2001.
}

When persons seek medical care, they are open to accepting guidance from an authority in whom they have entrusted their future well-being. There is much evidence that when health care professionals talk with their patients about risk reduction, illness management, and pharmacy use, those patients are more likely to change poor health habits, participate in screening, take medicines correctly, and reduce their use of unneeded health care services.

Given the potential that behavior counseling in routine medical care has to improve the health of individuals and the public, why isn't it used more widely? And when it used, how can it be used most effectively?

Those were among the questions that were the focus of a study that was recently completed by the Center for the Advancement of Health (CFAH). Based in Washington, D.C., the CFAH is an independent nonprofit organization that promotes greater recognition of how psychological, social, behavioral, economic, and environmental factors influence health and illness. The CFAH study, entitled "Integration of Health Behavior Counseling in Routine Medical Care," examined the role of physician training in the application of behavior counseling as well as health system impediments to and patient involvement in behavior counseling. And while the CFAH research project focused on those issues in the United States of America, the study may contain much information useful to other countries in the Americas dealing with similar concerns.

The CFAH research consisted of three related studies. In the first, 41 practicing physicians and other clinicians participated in roundtable discussions. The discussions focused on how participants view behavior change, how they approach it in practice, and what resources they need to be able to make use of the best available strategies for behavior change.

The second study consisted of interviews with program directors of 45 successful and innovative prevention programs delivered in health care settings. The objective of the interviews was to better understand how to develop and support prevention services as a regular part of medical care.

The third study comprised interviews with 55 leaders of organizations with a stake in the health research enterprise. These organizations included the National Institutes of Health (NIH) and other agencies of the Government of the United States, 
voluntary health organizations, and medical associations. Participants were asked to talk about the best ways for translating research into practice.

In their research for the three studies, the $\mathrm{CFAH}$ investigators were interested in four major issues:

- How do health care providers-particularly physicians-view health behavior counseling in routine care, and what determines whether they do it and do it effectively?

- What system-level factors influence the delivery of counseling?

- How is research on counseling translated into everyday practice?

- How do institutions such as professional societies, voluntary health organizations, the NIH, and other United States Government agencies see their role translating research into useful strategies for providers?

\section{BARRIERS TO BEHAVIOR COUNSELING}

The CFAH researchers found that there are reasons to be optimistic about incorporating behavior counseling into routine medical care. For example, there is interest in behavior counseling among clinicians and health systems. There are advocates, potential advocates, and leaders who could contribute to changes in clinical practice. There are opportunities for modest investments that would over time make counseling more effective. Some practitioners feel strongly that counseling is a key element of the care they provide. This is particularly true for practitioners who work with low-income patients. There are some good models for delivering counseling, including advice and diseasemanagement telephone lines staffed by nurses and health counseling and support approaches making use of the Internet.

Through the three studies, the CFAH also learned much about things that won't work, barriers to be overcome, approaches that have been tried and failed, and strategies that have surface validity but provoke hostility or indifference.

Among the barriers to wider, more effective use of behavior counseling in medical care, according to the CFAH study, are a variety of "myths," or assumptions that in part are based on fact but that also give an incomplete picture of the full reality.

One of the most important of these myths concerns the need for more research on behavior counseling. The belief is that more and better research would make clear the usefulness of counsel- ing to not only health plan purchasers and insurers but also physicians and individual consumers. A frequent comment that the CFAH researchers heard in their interviews with insurers and health plan decision-makers was that "there isn't enough evidence about the effectiveness and cost-effectiveness" of counseling as a part of routine medical care. The implication is that if only the evidence were available, such programs would be readily accepted.

However, the CFAH researchers believe that the perception of a lack of "evidence" is a convenient excuse for not implementing counseling, and that the issue of evidence is hardly straightforward. The difficulty with the "evidence" of counseling effectiveness in routine medical care is similar to the rest of health care: How much of what kinds of data and information are needed to be convincing? Complicating the case of counseling is that much of the evidence of effectiveness comes from disciplines that are unfamiliar and undervalued by health care decision-makers.

The efficacy and cost of counseling as part of medical care are documented almost exclusively by randomized controlled trials, of which there are many. Lacking, however, are descriptions of evaluated model programs and studies of the effectiveness of different implementation strategies and the short-term economic impact.

For their part, practitioners and consumers also have their doubts about behavior counseling. Practitioners say the available evidence on counseling in routine medical care does not apply to them or their patients, that the questions being studied are not the important ones, that the methods used to study them are not relevant, and that the information is not reported in venues and formats accessible to office-based practitioners.

Some clinicians are hostile to guidelines due to prior negative experiences. Physicians may view guidelines as top-down rules that obstruct their judgment, experience, and problem-solving. Clinicians generally feel that scientific findings about health behavior and their implications are not packaged and formatted into "tools" that the practitioners can easily integrate into their practice.

Many consumers do not have the time, interest, or inclination to understand risk estimates and other statistics and to figure out how a particular behavior or intervention might apply to their own lives. Further, these lay persons are often suspicious of "science" and "evidence," seeing them as expressions of big-money interests. Thus, the imprimatur of science may be a barrier for some individuals.

Scientific evidence becomes less importantand personal experience has greater potential to 
prevail over research-when the evidence is confusing or doesn't lead to clear recommendations. In such circumstances, clinicians often turn to colleagues as trusted sources of information, and patients turn to family and friends to help them figure out what to do.

Another misleading assumption that the CFAH found is that a market exists for counseling as part of routine medical care. Many advocates of counseling think that the rise of managed care in the United States would encourage implementation of such services. These advocates believe the demand for counseling would grow because of benefits to everyone. Employers would see increased productivity and less absenteeism. Health plans would experience lower utilization rates. Clinicians would have healthier patients. Patients would be more satisfied (and presumably less frequent) consumers of health care.

While appealing, that belief has difficulties in terms of both "demand" and "supply." With respect to demand, the CFAH found that clinicians and health care decision-makers are not asking for materials, tools, and insurance reimbursement for counseling as part of routine medical care because they are not convinced that counseling will produce the claimed benefits. There is also resistance to the role changes that counseling entails. Healthy patients see no need for counseling; physicians are skeptical and feel untrained and unable, due to time and financial pressure, to make sure patients receive counseling; and decision-makers believe the annoyance of changing traditional roles may outweigh any potential benefit.

On the supply side, there are too few clinicians who are prepared, willing, and able to deliver effective counseling as part of routine medical care, regardless of the specific discipline. There is also a shortage of robust behavior counseling models, techniques, and products that can be "sold." Most doctors are uninterested in becoming "suppliers" of behavior counseling interventions themselves and don't have the resources to delegate the responsibility within their practice.

\section{CROSS-CUTTING THEMES IN THE THREE STUDIES}

The three CFAH studies found that the clinicians, researchers, and other experts who were interviewed agreed on many issues in terms of how to successfully integrate health behavior counseling into routine medical care. Some of the common findings are described below.

\section{Clinicians and researchers are struggling to communicate with each other}

Clinicians and researchers still are searching for a common language. Clinicians and researchers tend to operate from different world views, have different information needs, and respond to different demands and incentives in their professional roles. For scientific and practical reasons, health behavior researchers are not investigating the questions of greatest interest to clinicians. The research that is being conducted often is perceived by clinicians as irrelevant to their everyday practices. Researchers are not uniformly trained to think about how their research could be translated into practice, and clinicians are not uniformly trained to interpret research into direct patient care.

Clinicians and researchers also do not always think about evidence in the same way. For clinicians, direct experience and the particular circumstances of a patient may be far more important in determining the appropriate treatment for that patient than evidence drawn from rigorous studies conducted with patients who are quite unlike the patients seen by the clinician every day.

\section{Health care professionals are receptive to new information from trusted sources}

In situations in which clinicians are asked to change their behavior or practices, information from colleagues-professional peers or professional societies-is considered more authoritative and trustworthy than information from most other sources. Clinicians are skeptical of information from sources that appear vulnerable to financial conflicts of interest, including pharmaceutical companies and managed care organizations. This means that guidelines, policy statements, and research about what works and what doesn't are more likely to reach a receptive audience when they come from professional societies, voluntary health organizations, and some agencies of the United States Government such as the Preventive Services Task Force.

\section{Effective counseling builds on physicians' skills}

Helping physicians implement effective counseling strategies will be based on what physicians feel capable of doing well, appropriate tools and system supports they need, and the expectation that they can't do it all. The notion that "one size 
does not fit all" became obvious in considering the question of who should conduct counseling as part of routine medical care. One strongly held view is that physicians are the ideal purveyors of health behavior change interventions. The opposing view-that physicians need not be involved-is held equally strongly. A third view is that there is an important role for physicians to play both in legitimizing health behavior counseling as part of routine medical care and as players on multidisciplinary collaborative care teams. Consensus about how to approach this issue was clear, however: no single implementation approach will be effective.

Organizations-from independent solo or group practices to large health maintenance organizations-must consider how best to implement high-quality counseling services in their local setting or delivery system. This means assessing physicians' willingness to counsel patients, the perceived barriers to physicians' involvement in providing this type of care, and things that would encourage physicians' participation.

To be successful in developing behavioral counseling program efforts, organizations should:

- involve physicians in designing roles for themselves that they feel are appropriate in providing health behavior counseling in their practice settings

- provide the tools and support that physicians need to feel confident in those roles

- clearly articulate the roles and responsibilities of all care providers

- make use of high-quality local community and nationally available materials and programs

\section{Consumers are not yet asking for health behavior counseling}

Patients are not demanding health behavior counseling in routine medical care, at least not so far. Some motivated individual consumers are asking for better programs, many are seeking health information from Internet sites, and many more are drawn to a variety of alternative therapies. Nevertheless, the participants in the CFAH studies identified no unified consumer voice or influence that will ignite or sustain the changes necessary to make health behavior counseling a part of routine medical care.

\section{There must be system-level components}

Some essential system-level components are critical—but not sufficient—for delivering effective counseling. Senior leadership and organizational commitment are key to successful health behavior counseling services in routine medical care. These services become a priority when leaders allocate both human and financial capital to ensure the effective delivery of care.

Robust clinical information systems are also essential. Good care is more likely when clinical information systems make it possible to identify patients who need counseling, prompt providers to deliver services, monitor services and outcomes, follow patients over the course of care, and provide feedback to both patients and providers.

\section{Models and tools are needed}

Many stakeholders want models and tools to help them do their jobs. Clinicians want and need tangible, practical instructions and methods to help them provide the counseling that will benefit their patients. Program developers and others who design interventions want validated models that spell out how behavior change happens. Health plans and decision-makers want examples of what successful programs look like and how the programs incorporate the necessary elements to help patients and providers change their behavior.

\section{SUCCESSFUL PREVENTION PROGRAMS IN HEALTH CARE SETTINGS}

The CFAH researchers interviewed program directors of 45 successful and innovative prevention programs in order to better understand the system-, program-, provider-, and patient-level supports that are important for the inclusion of prevention services as part of routine medical care. The CFAH's focus was on prevention services that are part of a health care delivery system rather than ones operating in the community or the workplace.

The prevention programs studied included ones for immunization, screening, and counseling on behavioral risk. The counseling programs dealt with such issues as tobacco cessation, weight management, physical inactivity, risky alcohol and substance use, sun safety, and general wellness. The immunization programs consisted of both child and adult immunization efforts. The screening programs primarily focused on mammography and cervical cancer screening. The majority of the programs looked at were located within managed care organizations.

Despite the variety in the programs examined, many similarities emerged. The following sections present some of the attributes that successful programs shared. The CFAH grouped its find- 
ings by organizational level, including: system (the larger organization in which the program is located), provider (clinician), and patient. Nevertheless, these levels do not exist in isolation. Rather, multiple approaches, involving multiple players and multiple supports, are necessary for effective prevention programs.

\section{The system level}

Successful programs, the CFAH found, have senior leaders in their organizations who are very involved in promoting preventive services. In addition, program goals are related to documented organizational priorities for prevention. Among other traits are: goals are outlined in business plans, strategic plans, and quality improvement plans; prevention programs are included as a covered benefit for patients; and programs are paid for through internal budgets.

Successful programs are supported by systemwide computerized clinical information systems. These systems can be used to identify patients in need of services and to generate reminders to physicians to attend to patient prevention needs such as flu shots and mammography.

\section{The provider level}

Physicians, nurses, and nurse practitioners were most often cited as the providers of prevention services. However, a wide range of other health care professionals could also play a role, including health educators, case managers, pharmacists, and physician assistants. Information systems specialists and fulfillment and/or mailroom staff are also vital in helping identify patients to target and sending them information.

Although physicians' roles vary across the programs, they generally involve being responsible for brief interventions with patients, including counseling about health behavior change, and then referring patients for additional services. Other health care providers are responsible for initially identifying need, prompting physicians to address issues, recording information accurately, conducting additional discussions with patients, and delivering longer-term interventions.

Physicians can also be program "champions," ensuring the development and implementation of health behavior change counseling programs and the integration of prevention activities into organizationwide priorities.

Traditional training techniques are being used to educate program staff on delivering pre- vention and health behavior change programs. The majority of programs rely on internal workshops, while a much smaller number use external workshops, conventional continuing medical education, Internet-based support, and peer feedback.

Slightly fewer than half of the programs include incentives to motivate providers to achieve program goals. Most of these incentives are financial, with compensation going to either providers or to departments or clinics that reach specific prevention goals. Programs also use certificates of achievement and other nonfinancial methods to recognize provider success.

\section{The patient level}

The behavior change services offered to patients most often include, in order of frequency, mailed materials, one-on-one sessions with providers, telephone calls, telephone hotlines for patients, group sessions, Internet-based services, and, in a few instances, home visits.

The majority of programs rely on traditional, passive patient education materials, such as pamphlets and newsletters, but many programs also utilize more personalized educational materials such as personal letters, tailored materials, and more interactive methods, including workbooks, videos, and Internet-based materials.

Some organizations conduct a health risk appraisal for at least some patients. This is done to identify individuals who may benefit from riskreduction counseling or other interventions, provide information to patients about their personal health, give clinicians information about their patients' health, and plan population-based behavior change services.

\section{Moving from research to practice}

Successful programs make use of research findings on health behavior change when designing prevention programs. Frequently mentioned were the so-called Transtheoretical Stages of Change Model and the National Cancer Institute's "4As" approach to smoking cessation (ask about smoking at every opportunity, advise all smokers to stop, assist the patient in stopping, and arrange followup visits). In addition, the programs sometimes apply traditional continuous quality improvement techniques.

Overwhelmingly, programs use formal clinical guidelines or protocols to deliver prevention services. Guidelines are primarily based on external resources such as agencies of the United States 
Government, voluntary health organizations, professional societies, and health plan collaboratives.

\section{RECOMMENDATIONS}

The recommendations contained in the CFAH report are multifaceted and address different stakeholders and potential points of leverage in the health care system, including clinicians, systemlevel decision-makers, health care delivery systems, and consumers. Each recommendation can be carried out individually and may be effective in creating some change in health care. However, creating substantial change is more likely when different approaches are coordinated.

\section{Clinicians}

In order to provide counseling as part of routine medical care, clinicians need tools that are tailored and formatted to meet their needs and answer their questions. Clinicians also need training that helps them to implement and integrate counseling in routine office visits. Finally, clinicians need evidence that specifically addresses the concerns they have about counseling patients. Specific recommendations covered the following areas.

Tools. Using currently available evidence collections, and with the input and consultation of clinicians, tools should be developed and disseminated. These tools should be based on a protocol derived from common elements of counseling interventions to change health risk behaviors and improve chronic disease management. These efforts will be more successful by working with trusted intermediaries, including professional societies and voluntary health organizations, to disseminate them.

Training. Training should be supported that helps clinicians to implement and integrate counseling into their day-to-day activities. Professional societies and other organizations should be identified that have an interest in counseling, that have the ability to reach their members with information and training, and that can help develop innovative approaches to continuing professional development.

Evidence. Evidence should be gathered that specifically addresses the concerns that clinicians have about counseling patients. Practitioners should have opportunities to work with health behavior researchers in developing research questions, so as to bring research and practice closer together.

\section{System-level decision-makers}

System-level decision-makers and clinicians need more information about successful programs. Incentives need to be in place to promote counseling as part of routine medical care. Specific recommendations included the two following areas.

Information on successful programs. There should be more information available about the implementation, effectiveness, and cost impact of successful programs as well as more evaluation funds and technical support to gather qualitative and quantitative information about successful programs. This information should include general programmatic approaches as well as implementation tools that encourage, prompt, monitor, track, and provide feedback on clinician performance. Implementation tools should be created that are adaptable to different settings.

Counseling as a quality improvement strategy. There should be opportunities for system-level innovators to implement counseling as a quality improvement strategy. Innovators should be recruited, especially those who work with vulnerable and underserved populations, to focus on systems changes to support the implementation of effective counseling as part of routine medical care.

\section{Health care delivery systems}

Health care delivery systems and the clinicians working in them cannot accommodate the full range of individual counseling needs of patients through just a brief office-based encounter. Patients vary in their needs and preferences for sources, formats, and venues for support and information to improve their health. Consequently, there should be a range of high-quality resources readily available to which clinicians can refer patients for more intensive, tailored, high-quality support to reduce risk, improve adherence, and manage chronic illness.

\section{Consumers}

Incorporating health behavior counseling into routine care is a long-term process involving changes at multiple levels. Engaging patients in this process is vital. In the future, it is likely that consumers will play a more powerful role in choosing their health care services and providers, and in making sure they receive high-quality care. Consumers may insist on having health behavior coun- 
seling available-but only when they can clearly see the potential health benefits to themselves. Mechanisms to facilitate consumer demand for behavior counseling are needed, including alliances with organizations that work with consumers to increase their engagement with their health and health care. The specific recommendations covered some of the following areas.

Consumer demand. Funding should be available so organizations can ask consumers about what kinds of behavior change support they expect and will accept from their health care providers. Resources are also needed to help identify the shortand long-term benefits of health behavior counseling and communicate these benefits to consumers.

Alliances. Alliances should be pursued with organizations and individuals that work to help consumers understand how to get the most out of the current health care system and services, how to evaluate and demand good care, and how to secure the most appropriate, least medically invasive treatment possible.

The full CFAH report provides more details on the results of the three studies as well as information on the persons interviewed and the interview questionnaires used to collect data. The full report is available on the CFAH Web site, at http:// www.cfah.org. In addition to this report, CFAH offers a variety of other materials dealing with the link that health and illness have to psychological, social, behavioral, economic, and environmental factors. Persons can also request a subscription to a free monthly e-mail newsletter that CFAH pro- duces with updates on its activities and the work of other organizations with similar concerns.

\section{SINOPSIS}

\section{Integración del asesoramiento sobre conductas sanas en la atención médica rutinaria}

Hay numerosas pruebas de que cambios de conducta sencillos y poco costosos pueden ayudar a los pacientes a mejorar su salud. No obstante, de acuerdo con un estudio publicado recientemente por el Centro para el Progreso de la Salud $(C F A H)$, organización independiente de carácter no lucrativo con base en Washington, D.C., estos resultados de las investigaciones no se trasladan a la práctica habitual del sistema de salud de los Estados Unidos de América con la frecuencia que sería de desear. Según el estudio del CFAH, la solución a este problema radica en incorporar el asesoramiento conductual a la rutina de los servicios de salud proporcionados tanto por los médicos como por las organizaciones sanitarias. La investigación del CFAH consistió en tres estudios relacionados entre sí. En uno se les pidió a los clínicos su opinión sobre los cambios de comportamiento y cómo los abordan en la práctica. En el segundo se les pidió a los directores de programas de prevención innovadores y exitosos que sugirieran formas de desarrollar esos servicios y de integrarlos en la atención médica habitual. En el tercero se les preguntó a los dirigentes de las organizaciones de investigación sanitaria cuáles eran, en su opinión, las mejores formas de llevar los resultados de la investigación a la práctica. El informe de CFAH describe las barreras al uso más amplio del asesoramiento conductual, identifica los temas comunes de estos tres estudios y recomienda medidas para integrar mejor el asesoramiento conductual en la atención médica habitual. 